\title{
A Study On Hrm Practices And Its Impact On Globalisation Of Indian Business.
}

\author{
Dr. C. Jothi Baskara Mohan \\ Asso.Professor, Dept. of Business Administration, Thiagarajar College,Madurai - 9.
}

\begin{abstract}
The rapidly changing business environment in India and abroad brings many challenges and some top of the mind business issues for companies. Today work force is undergoing radical change as a result of powerful global forces. This research paper, though exploratory in nature aims to help companies to understand the global and regional talent trends. Detailed research may be undertaken to equip the Indian organizations with knowledge to benchmark their talent management practices, identify the gaps in their programme, develop a road map for execution and generate innovative solutions to attract, engage, develop and retain their talent.
\end{abstract}

Keywords :- Business environment, talent management, global and regional trend.

The rapidly changing business environment in India and abroad brings many challenges and some top of the mind business issues for companies. Today work force is undergoing radical change as a result of powerful global forces. This research paper, though exploratory in nature aims to help companies to understand the global and regional talent trends. Detailed research may be undertaken to equip the Indian organizations with knowledge to benchmark their talent management practices, identify the gaps in their programme, develop a road map for execution and generate innovative solutions to attract, engage, develop and retain their talent.

\section{Indian Scenario}

The Indian economy is supported by huge inflow of FDI, raising foreign exchange reserves, an IT and real estate boom, developing capital market. The major critical strength for India is English speaking and relatively young work force, increasing domestic demand for goods and services, growth of domestic companies. However $60 \%$ of the India's 1.2 billion population is dependent on agriculture is a major challenge. Need for huge investment in infrastructure is another challenging area. Other areas which needs to be addressed are state bureaucracy, corruption and tariffs and the level of public debt.

\section{Methodology}

The findings presented in this paper are based on the data obtained from 10 top business managers and 4 management consultants. The survey and interview method was adopted for collecting the data. Based on the survey, the following results are presented. In this survey, the respondents were asked to indicate top business challenges among the important 10 challenges.

TABLE NO. 1

\begin{tabular}{|l|l|}
\hline BUSINESS CHALLENGES & RANK \\
\hline Cost pressure & 1 \\
\hline Retaining leaders and talent & 2 \\
\hline Addressing regulatory challenges & 3 \\
\hline
\end{tabular}

Rising cost is due to economic slowdown combined with oil and commodity prices, increasing wages and boom in real estate business is considered to be the first important challenge. Based on the survey, top human management challenges faced by Indian organizations are engaging their work force, retaining key employees and lack of leadership capability.the above was considered to be the second important challenge faced by the organizations. Addressing regulatory challenges was considered to be the third important challenge faced by the organizations in India.

\section{Major Challenges In Human Capital Management}

- The survey indicates that most of the Indian organizations are facing the challenges of bringing up employee engagement.

- Recruiting and retaining the key talent is another major challenge for Indian organizations in the changing global business environment. 
- Developing leadership capability is another significant challenge for Indian companies to achieve great success.

Based on the survey, the ranking of challenges of human capital management are presented here:

\begin{tabular}{|l|l|}
\multicolumn{2}{c}{ TABLE NO. 2} \\
\hline HR CHALLENGES & RANK \\
\hline Engaging work force & 1 \\
\hline Retaining the key employees & 2 \\
\hline Developing leadership skill & 3 \\
\hline
\end{tabular}

As higher level of engagement has strong positive correlation with key business results like total share holders return, customer satisfaction, retention, productivity, I asked the respondents to highlight the important strategies to be adopted.

\section{Strategies For Engaging Work Force}

Managing diversity is emerging as an important theme for managing engagement in an organization. Diversity means that different group of employees have different expectations and aspirations. Young employees expect higher level of remuneration ,fast faced growth and open communication. Similarly, older age group expect job stability, culture of respect and seniority.

- Develop and customize HR practices to each segment while maintaining common philosophy and principles.

- Provide enhanced responsibility levels, job rotation, targeted development programmes, action learning projects.

- Provide meaningful work, allocate task and responsibilities,alignment to intrinsic motivation and access to right resources.

- $\quad$ Build in some element of autonomy, the right amount of challenges and scope for innovation.

- Build total compensation programme that are customized.

\section{Retaining The Key Employees}

High performance employees are critical to the growth of any organizations. These people commonly demonstrate the capability to be the next generation leaders and responsible for company's future business growth. Recruiting and Retaining the key talent is very important to guide future business success. The survey clearly indicates that the above factor was considered to be the second most important challenge faced by Indian corporate leaders. The respondents highlighted the following strategies to be adopted for managing the above issues.

- Provide genuine opportunities for career advancement. Lack of real opportunities for advancement and professional growth within organizations result in the feeling of stagnation.

- As high potential teams are achievement driven individuals, achievement is measured in terms of pay. Hence, provide pay accurately reflect their level of contributions and personal efforts. In the minds of high potentials there is a direct relationship between performance, compensation and status.

- Provide flexible working arrangements.

\section{Lack Of Leadership Capability}

Developing leadership capability is another significant challenge. It is a key factor that differentiate successful companies from unsuccessful companies. The above factor was considered by most of the respondents as third important human resource management challenges in the $21^{\text {st }}$ century. Based on the respondents opinions, the following strategies may be adopted to manage the leadership challenge.

- Indian organizations need to focus on developing managers who can manage companies that are becoming global at present and in future.

- Focus on leadership capabilities such as the capacity to lead organizations, demonstrate visionary thinking as well as the ability to execute, hold the highest standards of ethics, develop others at all levels, understand the business as whole and built influential relationship with customers and shareholders.

- Systematically invest in leadership development programmes to create leaders at all levels. The important leadership skills such as vision and strategic thinking, ability to execute, ability to effectively develop other leaders. The leadership programmes needs to step out of the class room and involve experimental learning. 


\section{Conclusion}

India's knowledge workers are critical backbone of the country's economic growth.

All corporate leaders have understood the importance of managing human resources effectively to face the present and future business challenges. Since globalization of Indian business is inevitable, the HR managers should understand the challenges and the strategies to be adopted for managing the most important asset called human resources. Managing human asset will be the major challenge for future business in India and abroad.

\section{References:}

[1]. A. Monappa and M Engineer "Liberalisation and Human Resource Management", Response books, New Delhi (1999).

[2]. VSP Rao, Human Resource Management, Excel books, New Delhi (2009).

[3]. D. Ulrich,"A new mandate for Human Resources", Harvard Business Review, Jan-Feb 1998.

[4]. N. Papalexandris,"Downsizing and Outplacement:the Role of HRM, The International Journal of Human Resource Management.

[5]. B.H. Hravey, “Technology, Diversity and Work Culture: Key trends in the Next Millennium”, HR magazine, July 2000.

\section{Internet Sources :}

1. http://www.shrm.org

2. http://www.7_eleven.com

3. http://www.mancom.com. 